\title{
Electrospun Hybrid Microfibers of Polylactic Acid with Plasma Polypyrrole Particles with Ultrahydrophobic Surface for Biomedical Applications
}

\section{Fernando G. Flores-Nava}

Instituto Nacional de Investigaciones Nucleares

Guillermo J. Cruz

Instituto Nacional de Investigaciones Nucleares

Elena Colín-Orozco

Ciudad Universitaria

J. Cuauhtémoc Palacios

Ciudad Universitaria

Ricardo Valdivia-Barrientos

Instituto Nacional de Investigaciones Nucleares

Rosario Ramírez

Instituto Nacional de Investigaciones Nucleares

Maribel González-Torres

Tecnológico de Estudios Superiores de Tianguistenco

Olayo M. Guadalupe ( $\nabla$ guadalupe.olayo@hotmail.com )

Instituto Nacional de Investigaciones Nucleares https://orcid.org/0000-0002-7627-0563

\section{Research Article}

Keywords: Hydrophobicity, Polypyrrole Particles, Plasma, Polylactic acid, Electrospinning

Posted Date: July 9th, 2021

DOl: https://doi.org/10.21203/rs.3.rs-683095/v1

License: (c) (i) This work is licensed under a Creative Commons Attribution 4.0 International License. Read Full License 


\section{Abstract}

This work presents a study on the formation of hybrid electrospun fibers of polylactic acid (PLA) with insoluble polypyrrole (PPy) particles inside with the objective to prepare ultrahydrophobic fibers for biomedical applications. Krebs-Ringer and phosphate-buffered saline solutions were used as test solutions of human fluids. The PPy particles were synthesized by plasma with diameter in the 60-1000 $\mathrm{nm}$ range and were suspended in a PLA-chloroform solution with a PPy/PLA $=0.027$ mass ratio. PLA fibers with PPy particles inside were formed electrospinning this suspension obtaining diameters in the 0.12-9.0 $\mu \mathrm{m}$ range with average between 1.65 and $1.85 \mu \mathrm{m}$. Contact angles of the fibers with the test solutions were measured in the $113^{\circ}-147^{\circ}$ interval, most of them in the ultrahydrophobic $\left(120^{\circ}-150^{\circ}\right)$ region. The lowest angles were obtained with particles synthesized at the lowest power $(20 \mathrm{~W})$ and were like those obtained on PLA fibers. The highest angles were measured on the fibers with the particles synthesized at the highest synthesis power $(100 \mathrm{~W})$, with difference up to $15^{\circ}$. This difference in the angles was correlated with the resonant $\approx \mathrm{C} \approx$ groups of the particles through the fiber ultraviolet absorption.

\section{Introduction}

Electrospun hybrid fibers of polylactic acid (PLA) with polypyrrole (PPy) particles inside were prepared to study the hydrophilicity of the fibers to be applied in injured tissues in the central nervous system after a severe lesion to reconnect the lost communication in the lesion site [1, 2]. PPy films and particles have been applied before in spinal cord injuries with this purpose in laboratory animals with promising results [3-5]. PPy particles synthesized by plasma have structures of complex networks of aliphatic and aromatic amines and are practically insoluble due to their high crosslinking resulting from the constant collisions of the monomers with the accelerated plasma particles during the synthesis [6]. The insolubility makes PPy practically unable to obtain microfibers by electrospinning, as this technique needs soluble polymers to eject fine flows of solutions from one electrode to another in a high voltage field. To overcome this problem, it is necessary to use a soluble polymer as PLA to carry the PPy particles in this travel between electrodes $[7,8]$, which end in the interior of the fibers.

PPy particles inside such fibers would do their job during the slow degradation of the fibers in the injured site. However, particles in fibers reduce the fiber wettability, which also reduces their degradation. Considering these problems, this work combines particles and fibers to study their affinity with water, Krebs-Ringer (KR) and phosphate buffered saline (PBS) solutions, which have salt concentration similar to human fluids, in order to indirectly evaluate the hydrophilicity between fibers and human fluids through their contact angle $(\theta)$.

Among other uses, contact angles can be applied in the life estimation of an implant in the body. In general, higher angles indicate slower degradation, because the first degradation step is the implant wetting; however, it is also the first step in the interaction with the surrounding tissues. Drug delivery can also be seen in this way because it usually depends on the degradation of the carrier $[9,10]$. Many works 
have been done modifying surfaces to increase or decrease contact angles. For example, smooth surfaces have low angles, which increase with the roughness. For the same chemical structure, higher angles can be obtained combining protrusions with different magnitude [11, 12]. In 2018, Thomas manufactured hydrophobic electrospun fibers of PLA and chitosan finding a relation among roughness, fiber diameter and the surface energy [13]. Varesano in 2013 synthesized polypyrrole-coated hydrophobic fibers using oleic acid as a dopant obtaining a contact angle of $111^{\circ}[14]$.

\section{Experimental}

PPy films and particles were synthesized by plasma polymerizing Pyrrole (Aldrich, 98\%) using glow discharges in a resistive arrangement with a vertical tubular glass reactor $9 \mathrm{~cm}$ diameter and $30 \mathrm{~cm}$ length at $13.56 \mathrm{MHz}$ and $10^{-1} \mathrm{mbar}$. A magnetic field was applied in the lower electrode. Two synthesis powers were used, $20 \mathrm{~W}$ and $100 \mathrm{~W}$, to evaluate the hydrophobicity with a slightly different PPy chemical structure. In plasma polymers, crosslinking usually increases with the power of synthesis. The particles were collected in the region of highest magnetic field, see Fig. 1b, because the electron density and the probability of an ionizing collision with other particles is higher in this region [15]. Approximately, $27 \mathrm{mg}$ of PPy particles were obtained in each synthesis, named as PPy20 and PPy 100 to include the power of the synthesis in the name of the particles. Figure $1 \mathrm{~b}$ shows the PPy fractions obtained in the synthesis: soluble and insoluble films, and insoluble particles.

The particles were added to PLA dissolved in chloroform forming homogeneous dispersions with a PPy/PLA $=0.027$ mass ratio. The mixture was injected into an electrospinning machine designed and built by the team of this work with an injection speed of $1 \mathrm{~mL} / \mathrm{h}$ at $12.2 \mathrm{kV}, 12 \mathrm{~cm}$ distance between electrodes, internal needle diameter of $400 \mu \mathrm{m}$ and $2500 \mathrm{rpm}$ rotation collector. Sheets of fibers were obtained in this way, see Fig. $1 \mathrm{~b}$.

The fiber morphology was studied by scanning electron microscopy (SEM) with a Jeol IT 100 apparatus and by transmission electron microscopy (TEM) with a Jeol JEM-2010 microscope. The chemical structure was studied by infrared (IR) spectroscopy (FT-IR i5 Thermo Scientific) with attenuated total reflectance (ATR) using a diamond cell in the $550-4000 \mathrm{~cm}^{-1}$ range.

The hydrophilicity of the polymers was evaluated measuring the contact angles in advance static mode with drops of water, KR and PBS solutions, see the salt concentration in Table 1. Consecutive drops of 2 $\mu \mathrm{L}$ were deposited on the polymers, up to $30 \mu \mathrm{L}$, in a Rame-Hart 250 goniometer. 15 photographs were taken observing the evolution of the angles evaluated with tangents of the drops at the coexistence point of the solid, liquid and gas phases.

Figure 2 shows photographs of a water droplet on a PPy film (a) and on electrospun hybrid PLA/PPy fibers (b) to exemplify hydrophilic and hydrophobic contact angles. The interfacial, Gas-Solid $\left(\gamma_{G S}\right)$, SolidLiquid $\left(\gamma_{S L}\right)$ and Gas-Liquid $\left(\gamma_{G L}\right)$ forces are shown as arrows in Fig. 2. The equilibrium of forces has been 
fixed in $\theta=90^{\circ}$, where $Y_{G S}=Y_{S L}$; however, if the surface forces are greater, $\theta<90^{\circ}$, the surface becomes hydrophilic, $Y_{G S}<Y_{S L}$, otherwise the surface is hydrophobic, $\theta>90^{\circ}$, where $Y_{G S}>Y_{S L}[16-20]$.

Table 1

Concentration (mM) of solutions KR and PBS.

\begin{tabular}{|llllllll|}
\hline Solution & $\mathrm{NaCl}$ & $\mathrm{Na}_{2} \mathrm{HPO}_{4}$ & $\mathrm{KH}_{2} \mathrm{PO}_{4}$ & $\mathrm{KCl}$ & $\mathrm{CaCl}_{2}$ & $\mathbf{M g S O}_{4}$ & $\mathrm{NaHCO}_{3}$ \\
\hline KR & 118 & & 1.3 & 4.7 & 2.5 & 1.17 & 25 \\
\hline PBS & 24 & 10 & 3 & & & & \\
\hline
\end{tabular}

\section{Results And Discussion}

\subsection{Morphology}

Figures 3a and 3b shows SEM micrographs of agglomerated quasi spherical PPy particles. The average diameter and data dispersion were calculated with a normal distribution function (Eq. 1), where $\phi$ is diameter, $\mu$ is the mean and $\sigma$ the standard deviation. Figure $3 c$ shows the harmonic distribution of the diameter measured with approximately 1500 particles calculated in the 60-1000 nm range with mean in 240 and $272 \mathrm{~nm}$ for PPy 20 and PPy 100, respectively. The data dispersion was calculated measuring the full width at half maximum (FWHM) of the distribution, FWHM/2 was 330 and $140 \mathrm{~nm}$ for PPy20 and PPy100, respectively. The plot indicates that as the synthesis power increases, the diameter dispersion decreases.

$$
f(\phi)=\frac{1}{\sigma \sqrt{2 \pi}} e^{-\frac{1}{2}\left(\frac{\phi-\mu}{\sigma}\right) 2}
$$

SEM micrographs of the electrospun fibers are shown in Fig. 4. PLA fibers were obtained as a reference for the hybrid fibers. The PLA micrograph presented in Fig. 4a shows fibers with circular profile and smooth surface. Figures $4 b$ and $4 c$ show PPy/PLA hybrid fibers prepared with PPy particles; they also have circular profile with protuberances that suggest the presence of particles inside. Such protuberances are not observed in PLA fibers.

Figure 5a shows the diameter of fibers calculated with Equation 2 in the 0.12-9.0 $\mu \mathrm{m}$ range with harmonic mean in 1.34, 1.65 and $1.85 \mu \mathrm{m}$ with FWHM/2 of $1.04,1.97$ and $1.34 \mu \mathrm{m}$ for PLA, PPy20/PLA and PPy100/PLA, respectively. The smallest mean diameter belongs to PLA, PPy20/PLA is in the middle and the largest diameter belongs to PPy100/PLA fibers. The plot indicates that as the synthesis power increases, the diameter dispersion decreases. Note that the diameter of fibers is approximately 6 times greater than that of the particles. Considering that the needle internal diameter was $400 \mu \mathrm{m}$ in the electrospinning device, which is the exit diameter of the polymeric flow, the diameter of the final fibers was approximately 200 times smaller. An approximation of the distance among fibers was calculated in 
the $0.24-21.25 \mu \mathrm{m}$ range with harmonic mean in $2.54,3.21$ and $3.28 \mu \mathrm{m}$ with $\mathrm{FWHM} / 2$ of $4.57,3.56$ and $5.16 \mu \mathrm{m}$ for PLA, PPy20/PLA and PPy100/PLA, respectively, see Figure 5b. These numbers are important to house neuronal cells which have soma of approximately $5 \mu \mathrm{m}$. So, they can fit approximately in the interspace of these fibers.

TEM micrographs in Fig. 6 reveal that some of the protuberances shown in the SEM micrographs of the hybrid fibers presented in Fig. 5, belong to particles inside. Figure 6a shows the particles in lighter gray color marked with a gray circle.

\subsection{Hydrophobicity}

Figure 7 shows the contact angles of the fibers as a function of the drop volume with water (Fig. 7a), KR (Fig. 7b) and PBS solutions (Fig. 7c). Contact angles on fibers and particles cannot be measured individually with this technique because it is essentially for continuous or semi continuous surfaces, so the angles on the fibers were measured on the fibered sheets shown in Fig. 1c. An approximation of the contact angles on PPy was measured on films obtained in other fractions of the same synthesis.

Most angles of the test solutions on PPy films were in the $70^{\circ}-85^{\circ}$ interval, located in the hydrophilic zone, barely reducing in general as the drop volume increases. In almost all cases, PPy 100 had greater angles than PPy20. The angles on PLA and on PPy/PLA fibers were between $115^{\circ}$ and $145^{\circ}$ located in the ultrahydrophobic zone, increasing with the drop volume $[11,12]$. As in PPy films, PPy100/PLA had much greater angles than PPy20/PLA. Note how the angles increased from the hydrophilic PPy films to the ultrahydrophobic PPy-PLA fibers in the three test solutions, especially with PPy100. Implants for the human body prepared with hydrophilic fibers can be associated with a rapid degradation in the body and as the angles increase the degradation reduces.

\subsection{Chemical groups}

As it was mentioned before in the introduction, contact angles are influenced by physical and chemical variables; however, if the physical variables are not so much different, which is the case of this work, then the differences in the angles could be attributed to the chemical characteristics, as polarity of molecules and/or resonant groups. Figures $8 \mathrm{a}$ and $8 \mathrm{~b}$ show a representation of the chemical structure of PLA and crosslinked PPy, and Fig. $8 \mathrm{c}$ shows the respective IR scans of the electrospun fibers and particles in the $550-4000 \mathrm{~cm}^{-1}$ interval. The main absorptions are labeled with the respective associated chemical groups. This analysis allows the identification of the main chemical groups.

The highest IR absorption in PPy particles belongs to $C=C$ groups centered in $1631 \mathrm{~cm}^{-1}$ with almost no differences respect to the synthesis power. The only difference in the particles synthesized at different power is the signal centered in $2358 \mathrm{~cm}^{-1}$, which is greater in PPy100 than in PPy20. This absorption has been associated with resonant $\approx \mathrm{C} \approx$ groups in plasma polymers with heterocyclic rings, which can be associated with long unions of conjugated $-\mathrm{C}=$ groups and suggests that higher dehydrogenation and crosslinking happens at higher synthesis power [21]. This difference is lost in PPy/PLA hybrid fibers because the structure of PLA predominates in the fibers due to the low PPy/PLA $=0.027$ mass ratio used. 
The most significative PLA peaks are centered in 1750 and $1082 \mathrm{~cm}^{-1}$ which belongs to $\mathrm{C}=0$ and $\mathrm{C}-0$ groups.

Thus, as the hybrid fibers have the same PPy/PLA mass ratio with similar diameter of PPy particles and fibers, the higher angles measured in PPy100/PLA fibers could be associated to resonant $\approx C \approx$ groups which were detected in the IR scans of PPy 100 and practically were not detected in PPy 20 particles. This chemical group may affect the electromagnetic absorption of the fibers, which is discussed in the following section.

The UV-Vis absorption of materials can be associated with the electronic distribution of their chemical groups. Some materials are hydrophobic but become hydrophilic when exposed to UV light due to slight chemical changes on the surface. Figure 9 shows the UV-Vis absorption of PPy particles, PLA and PPy/PLA fibers as a function of the incident wavelength in the $200-850 \mathrm{~nm}$ interval. In general, it is observed that the materials absorb with a higher intensity in the ultraviolet region, 200-350 nm, decreasing as wavelength increases. The absorption in the fibers remained almost constant in the Visible interval.

Both PPy particles have similar absorption with peaks in 276 and $281 \mathrm{~nm}$. PLA fibers have the lowest absorption with peaks in 236 and $276 \mathrm{~nm}$, and PPy/PLA fibers have absorption between PLA and those of the particles. PPy20/PLA fibers have absorption similar to PLA and PPy100/PLA fibers have a more intense absorption in the UV region, as PPy particles with maximum in $250 \mathrm{~nm}$. As it was mentioned before, the main difference in the chemical groups of the particles is the presence of $\approx \mathrm{C} \approx$ groups in PPy 100 particles, which is strongly marked in the UV absorption. The resonance of this group could be the reason of the greater contact angles of PPy100/PLA fibers respect to PPy20 PLA fibers.

\section{Conclusions}

Hybrid fibers of PLA with insoluble semi-spherical PPy particles inside were prepared by electrospinning for biomedical applications. The particle diameter was in the 60-1000 nm interval with mean between 240 and $272 \mathrm{~nm}$. The mean fiber diameter was between 1.34 and $1.85 \mu \mathrm{m}$ with mean gap among fibers between 0.24 and $21.25 \mu \mathrm{m}$. Many biological cells fit in this space. The hydrophobicity of the fibers was evaluated measuring the contact angles of the fibers with water, KR and PBS solutions, which have similar salt concentration to human fluids. The angles obtained on the fibers were between $113^{\circ}$ and $147^{\circ}$, which indicates that they are in the ultrahydrophobic region $\left(120^{\circ}-150^{\circ}\right)$. However, the angles on the fibers had different values depending on the power of synthesis of the PPy particles. The lowest angles were obtained with particles synthesized at the lowest power $(20 \mathrm{~W})$ and were like those obtained on PLA fibers. The highest angles were measured on the fibers with the particles synthesized at the highest synthesis power $(100 \mathrm{~W})$, with difference up to $15^{\circ}$. As the physical variables in the electrospun fibers were similar, with the same PPy/PLA mass ratio and similar diameter of particles and fibers, this effect was associated to chemical variables as the resonant $\approx C \approx$ groups detected in the particles. These groups were also associated with a higher electromagnetic absorption of PPy particles synthesized at 
higher power. These results can be applied in preparing hybrid PPy/PLA electrospun fibers with controlled hydrophobicity for biomedical applications.

\section{Declarations}

\section{Acknowledgment}

The authors thank CONACyT for the financial support to FC-152 project and for the scholarships given to Fernando G. Flores-Nava and Rosario Ramírez.

\section{Conflict of interest}

The authors of this work declare that there is no conflict of interest regarding the publication of this paper.

\section{References}

1. Y.F. Goh, I. Shakir, R. Hussain, J. Mater. Sci. 48, 3027, (2013)

2. P. Sensharma, G. Madhumathi, R.D. Jayant, A.K. Jaiswal, Mater. Sci. Eng. C 77, 1302 (2017)

3. G.J. Cruz, R. Mondragón-Lozano, A. Diaz-Ruiz, J. Manjarrez, R. Olayo, H. Salgado-Ceballos, M.G. Olayo, J. Morales, L. Alvarez-Mejía, A. Morales, M. Méndez-Armenta, N. Plascencia, M.C. Fernandez, C. Ríos, J. Mater. Sci: Mater. Med. 23, 2583 (2012)

4. R. Mondragon-Lozano, C. Rios, E. Roldan-Valdez, G.J. Cruz Cruz, M.G. Olayo, R. Olayo, H. SalgadoCeballos, J. Morales, M. Mendez-Armenta, L. Alvarez-Mejia, O. Fabela, A. Morales, S. Sánchez-Torres, A. Diaz-Ruiz, The Spine J. 17, 562 (2017)

5. L. Alvarez-Mejia, J. Morales, G.J. Cruz, M.G. Olayo, R. Olayo, A. Diaz-Ruiz, C. Rios, S. Sánchez-Torres, A. Morales-Guadarrama, O. Fabela-Sánchez, R. Mondragón-Lozano, H. Salgado-Ceballos, J. Mater. Sci: Mater. Med. 26, 554 (2015)

6. G.J. Cruz, M.G. Olayo, O.G. López, L.M. Gómez, J. Morales, R. Olayo, Nanospherical particles of polypyrrole synthesized and doped by plasma, Polymer, Vol 51, 4314-4318, (2010)

7. M. Gajendiran, J. Choi, S.J. Kim, K. Kim, H. Shin, H.J. Koo, K. Kim, J. Ind. Eng. Chem. 51, 12 (2017)

8. T. Abudula, U. Saeed, A. Memic, K. Gauthaman, M.A. Hussain, H. Al-Turaif, J. Polym. Res. 26, 110 (2019)

9. M. González-Torres, G.J. Cruz-Cruz, V. Sánchez-Mendieta, L.M. Gómez-Jiménez, F. González-Salgado, R. Mondragón-Lozano, M.G. Olayo-González, Polym. Bull. 74, 1761 (2017)

10. M. González-Torres, M.G. Olayo, L.M. Gómez, J. Morales, R. Olayo, R. Ramírez, F.G. Flores, M.R. MejíaCuero, G.J. Cruz, Polym Bull. 77, 375 (2020)

11. B. Bhushan, Y.C. Jung, M. Nosonovsky, Springer Handbook of Nanotechnology. (Springer, Berlin 2010) pp. 1453-1467

12. P. Roach, N.J. Shirtcliffe, M.I. Newton, Soft Matter. 4, 224 (2008) 
13. T. Zhao, L. Jiang, Colloid Surf B: Biointerfaces. 161, 324 (2018)

14. A. Varesano, F. Rombaldoni, C. Tonetti, Fibers and Polym. 14, 703 (2013)

15. P.J. Kelly, R.D. Arnell, Vacuum 56, 159 (2000)

16. M. Lazghab, K. Saleh, I. Pezron, P. Guigon, L. Komunjer, Powder Technol. 157, 79 (2005)

17. P. Nikolopoulos, S. Agathopoulos, A. Tsoga, J. Mater. Sci. 29, 4393 (1994)

18. F. Rupp, L. Scheideler, J. Geis-Gerstorfer, Chem. Eng Technol. 25, 877 (2002)

19. G. Agrawal, Y.S. Negi, S. Pradhan, M. Dash, S.K. Samal, Characterization of Polymeric Biomaterials. 57 (2017)

20. T. Zhao, L. Jiang, Colloid Surf B: Biointerfaces. 161, 324 (2018)

21. L.M. Gómez, M.G. Olayo, M. González-Torres, J. Morales, R. Olayo, M.R. Mejía-Cuero, G. J. Cruz, J. Inorg. Organomet. Polym. 28, 2742 (2018)

\section{Figures}

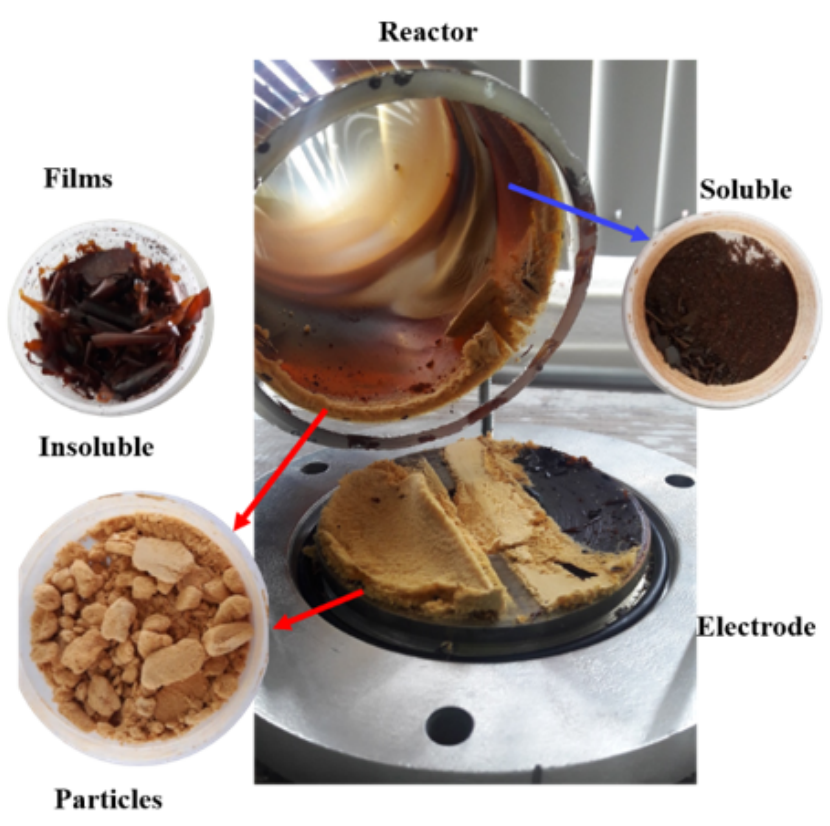

a) PPy fractions obtained

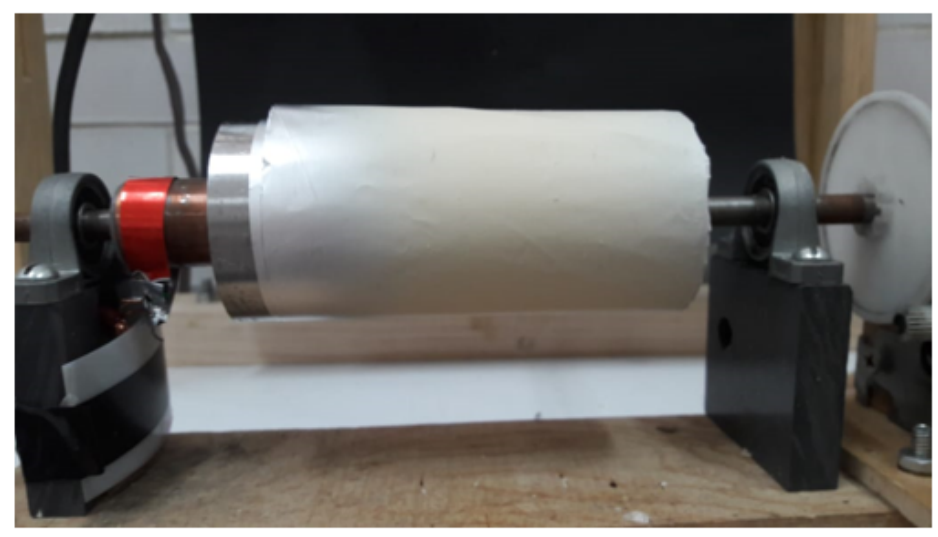

b) Sheet of hybrid electrospun PPy/PLA fibers.

\section{Figure 1}

a) Soluble and insoluble PPy fractions synthesized, films and particles. b) Sheet of PPy/PLA electrospun fibers. 


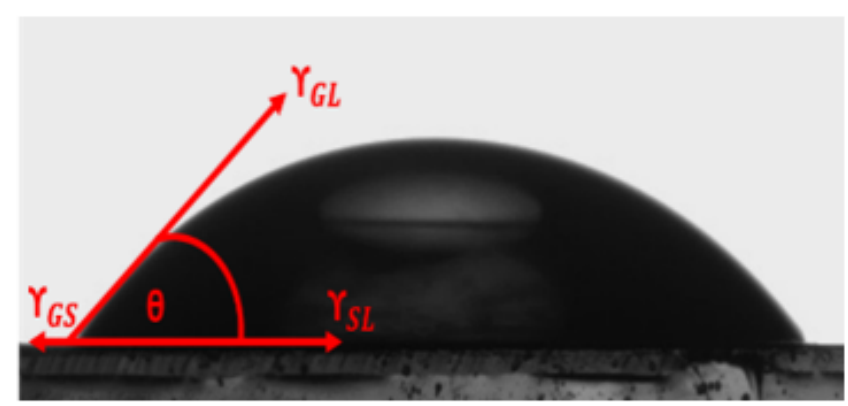

a) Hydrophilic PPy films

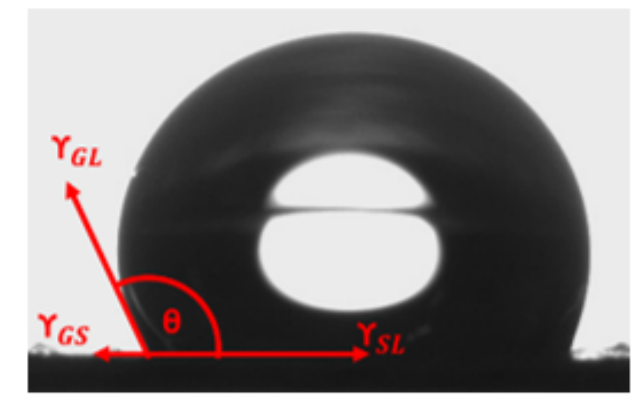

b) Hydrophobic electrospun PLA/PPy fibers

\section{Figure 2}

Photographs of water droplets deposited on PPy films and hybrid PLA/PPy fibers. 


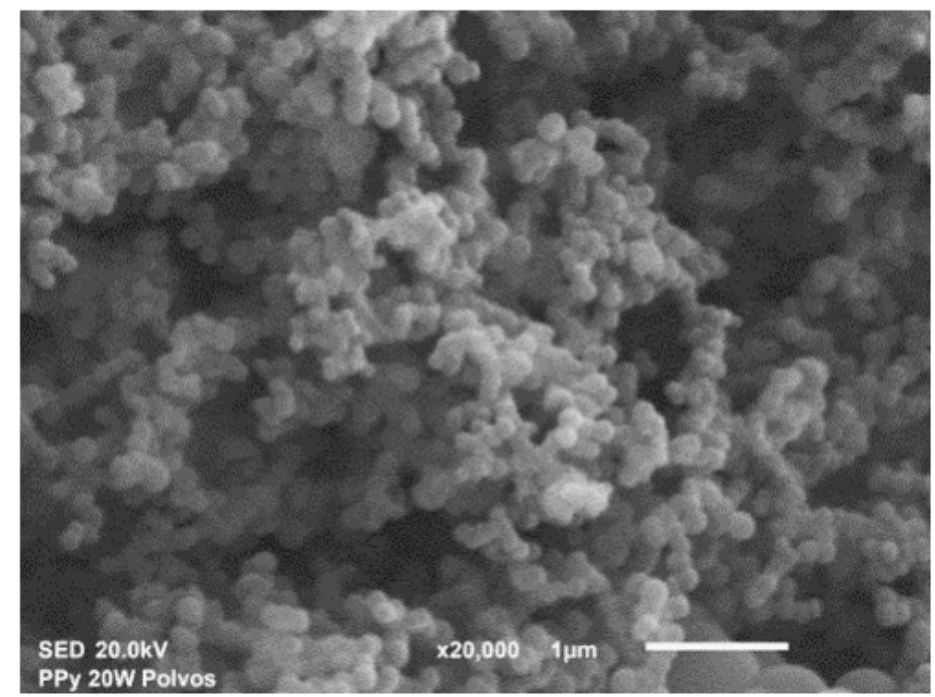

a) PPy $20 \mathrm{~W}$

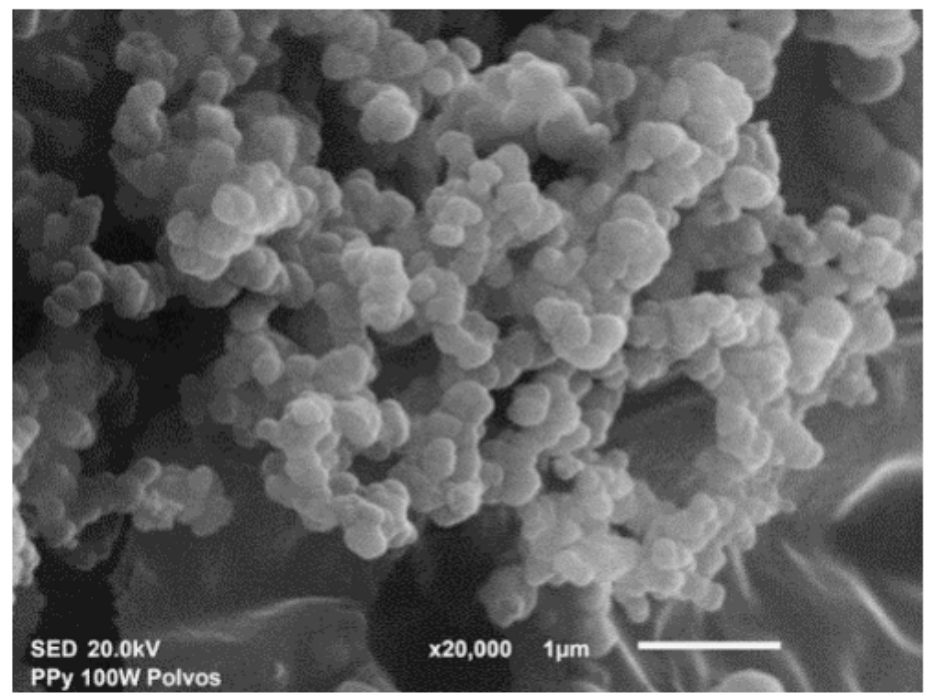

b) PPy $100 \mathrm{~W}$

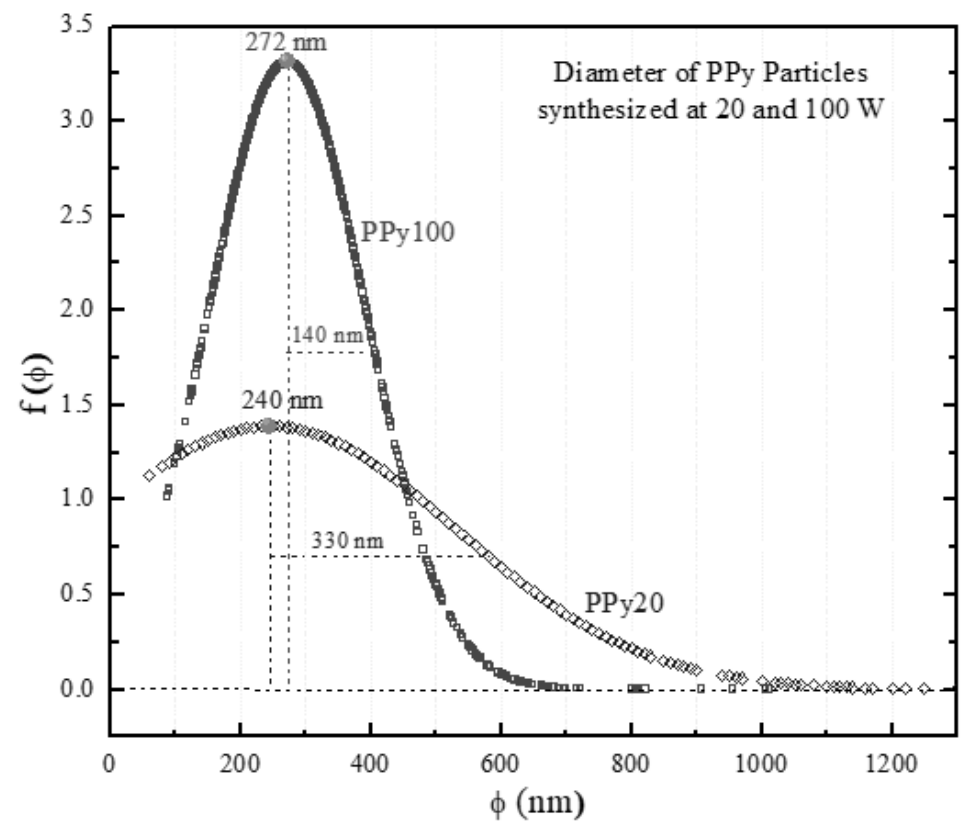

c) Diameter of PPy particles

\section{Figure 3}

Morphology and diameter of PPy particles. 


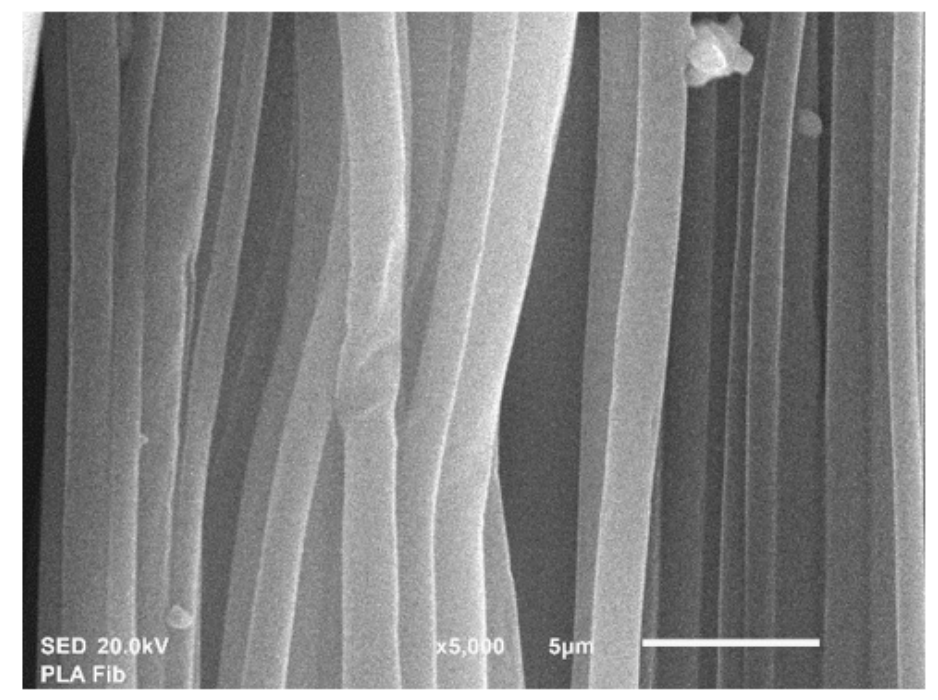

a) PLA

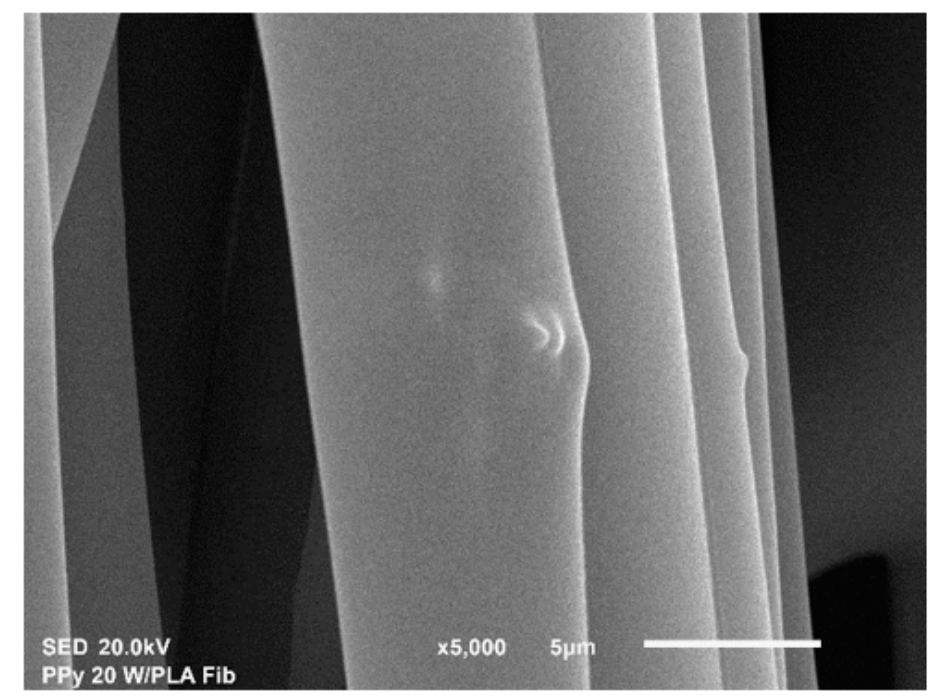

b) PPy20/PLA

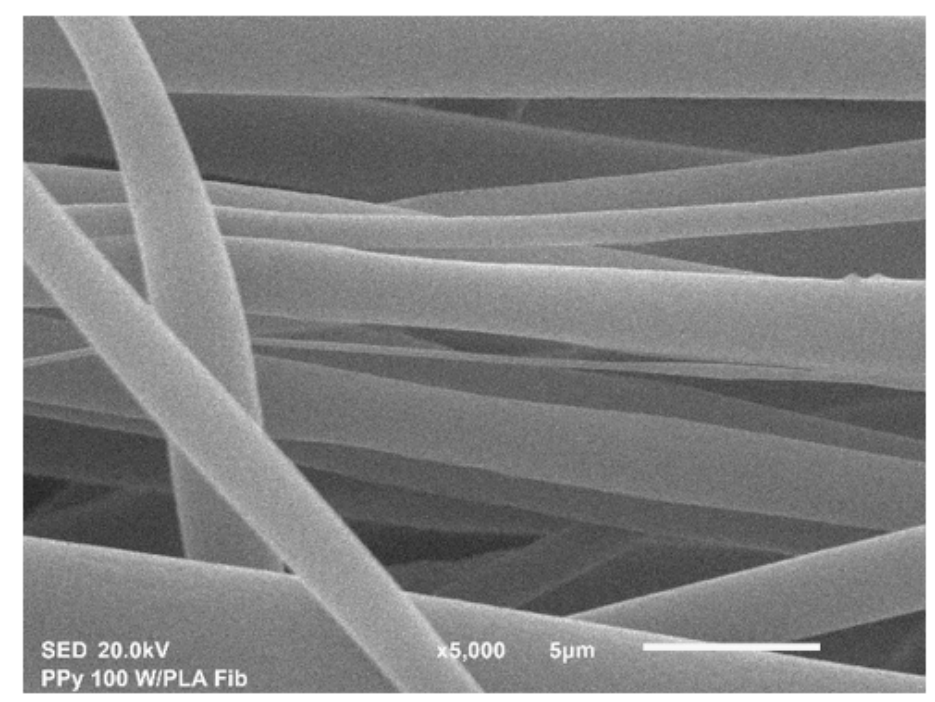

c) PPy100/PLA

\section{Figure 4}

SEM micrographs of PLA and hybrid electrospun fibers with PPy particles synthesized at 20 and $100 \mathrm{~W}$. 


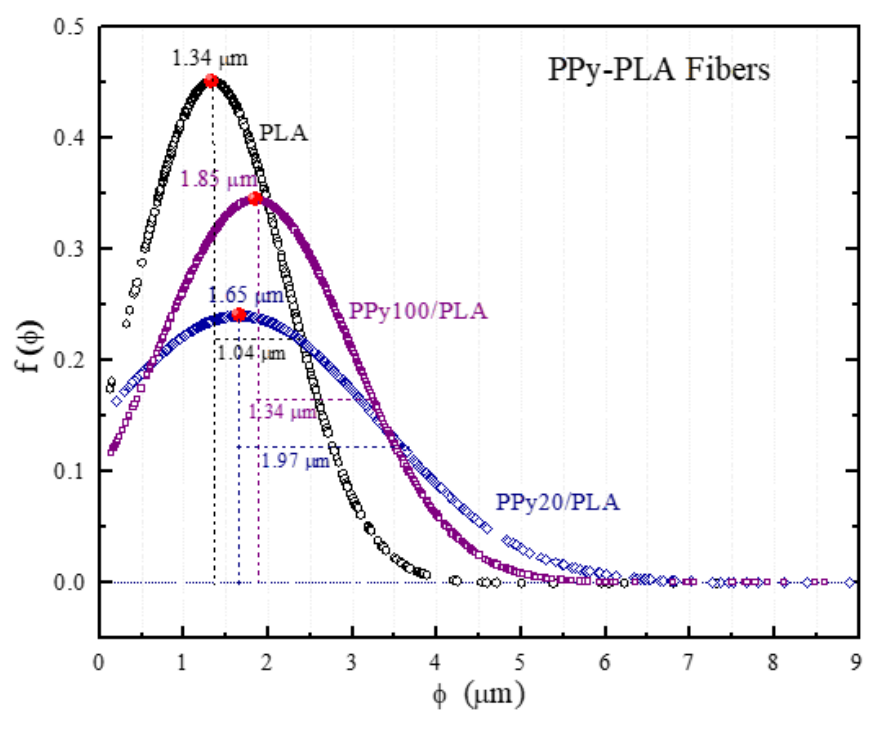

a) Diameter of fibers

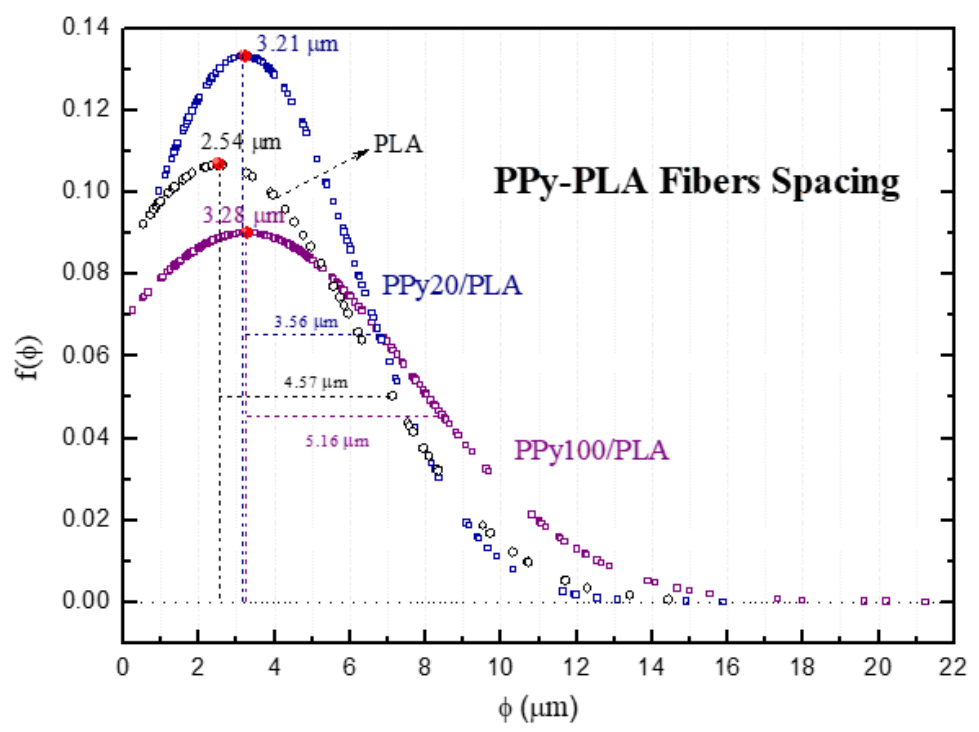

b) Spacing among fibers

\section{Figure 5}

Diameter and spacing among fibers.

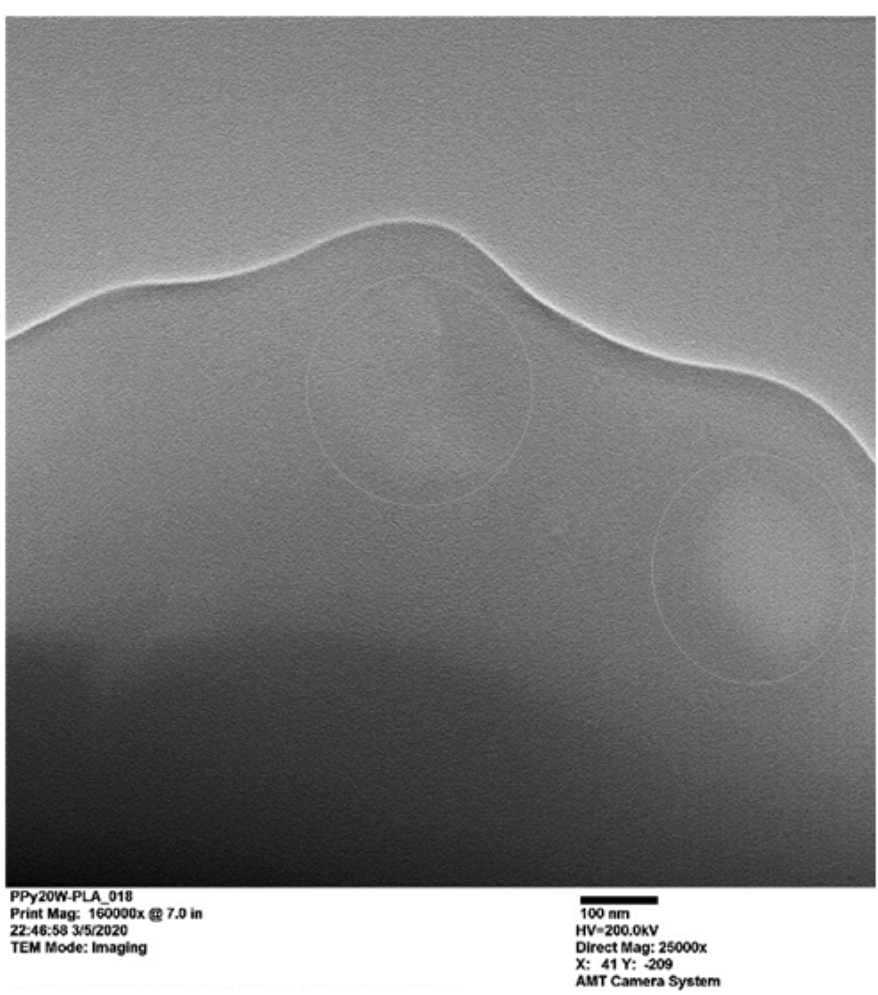

a) PPy20/PLA

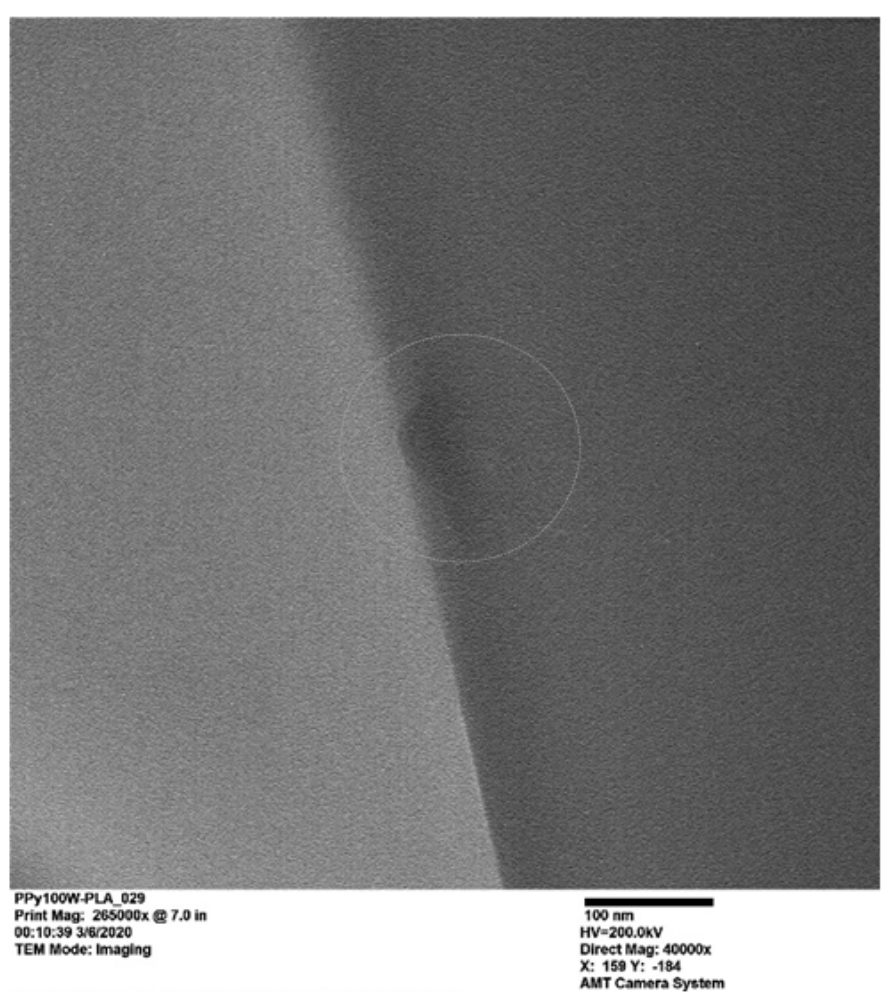

b) PPy100/PLA

\section{Figure 6}

TEM micrographs of PLA and hybrid electrospun fibers with PPy particles synthesized at 20 and $100 \mathrm{~W}$. 


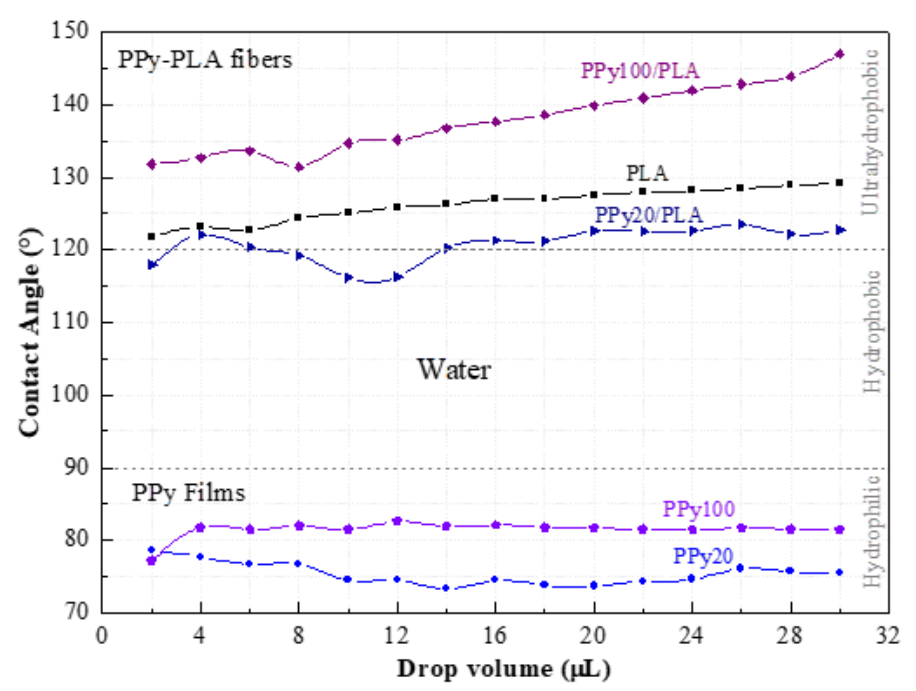

a) Water

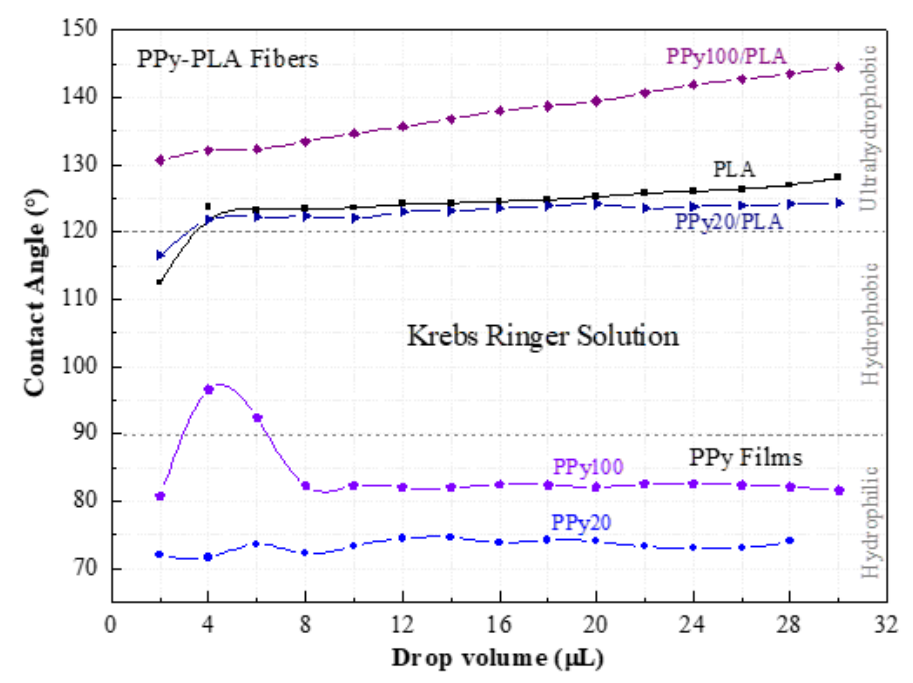

b) KR solution

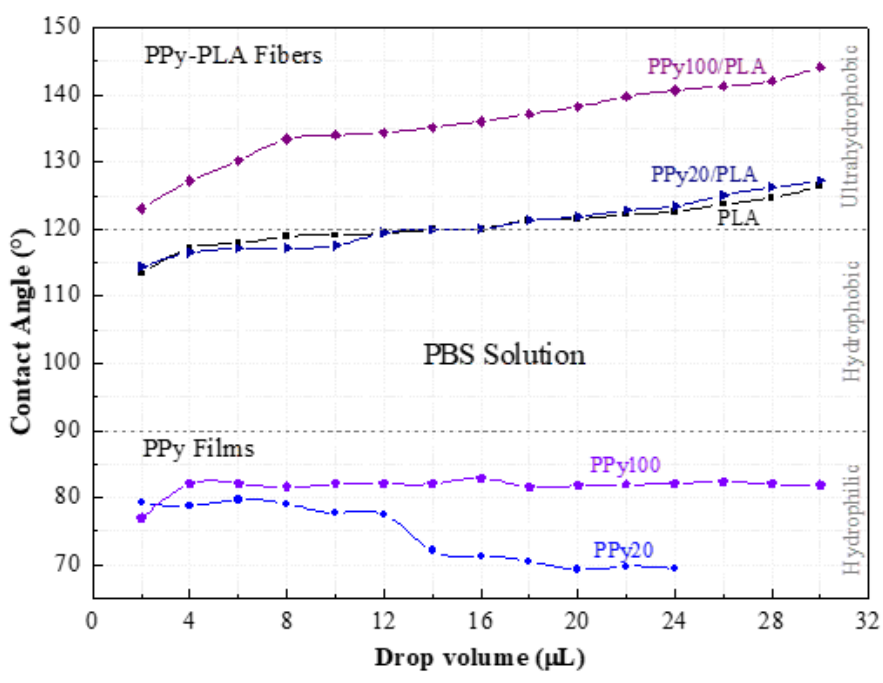

c) PBS Solution

\section{Figure 7}

Contact angles of PPy films and PLA and PPy/PLA fibers with a) water, b) KR and c) PBS solutions. 


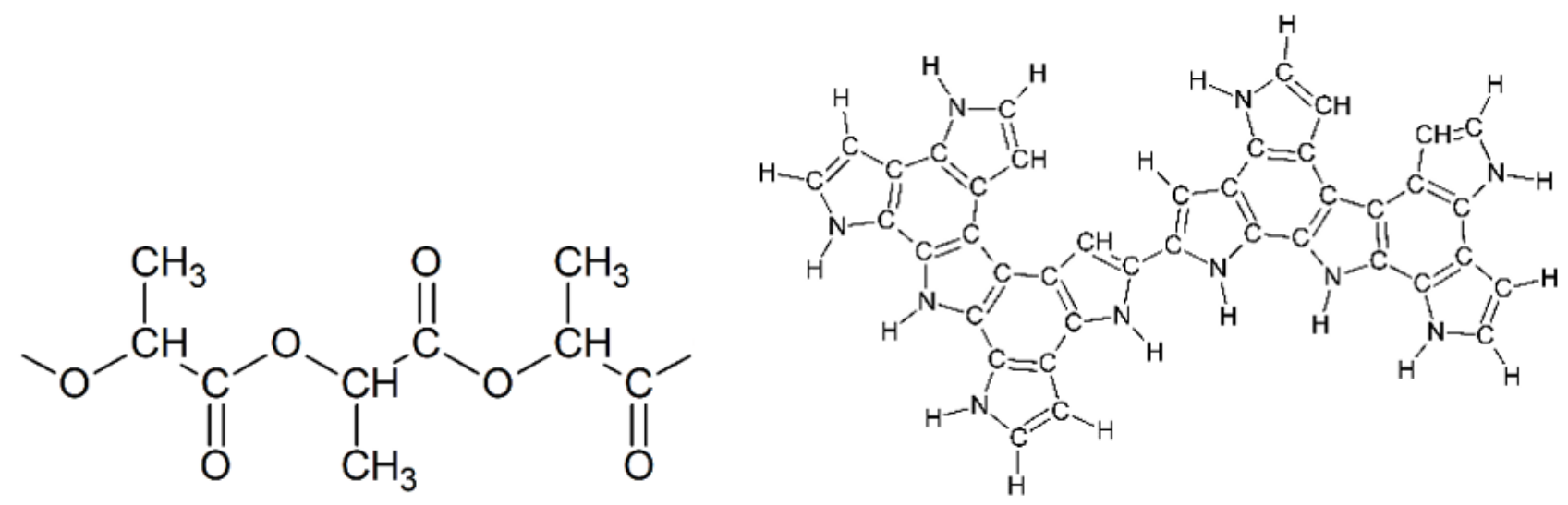

a) PLA

b) Crosslinked PPy

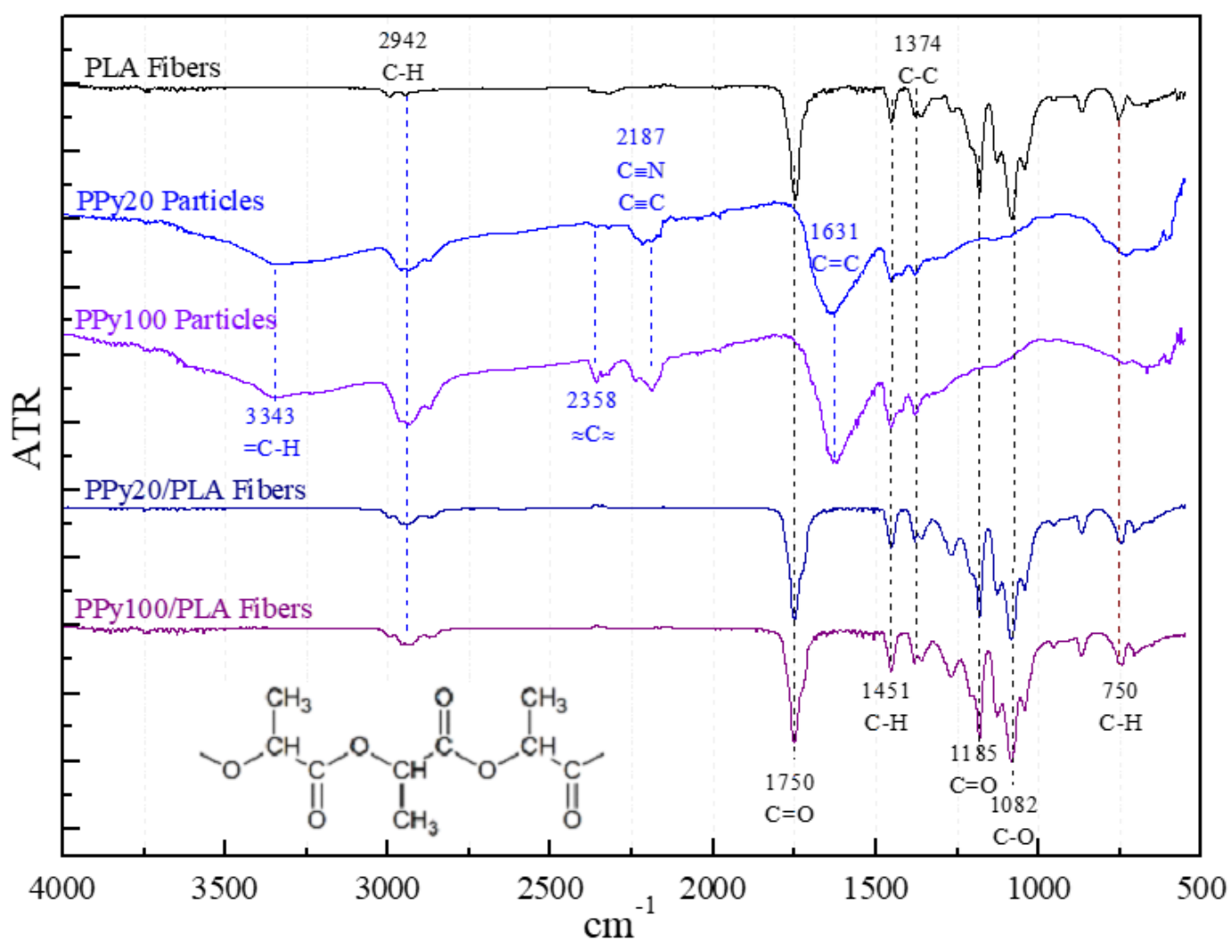

c) IR of PPy particles, PLA and PPy/PLA fibers.

\section{Figure 8}

Representation of chemical structures of: a) PLA and b) PPy particles. c) IR of PPy particles and PLA, PPy/PLA electrospun fibers. 


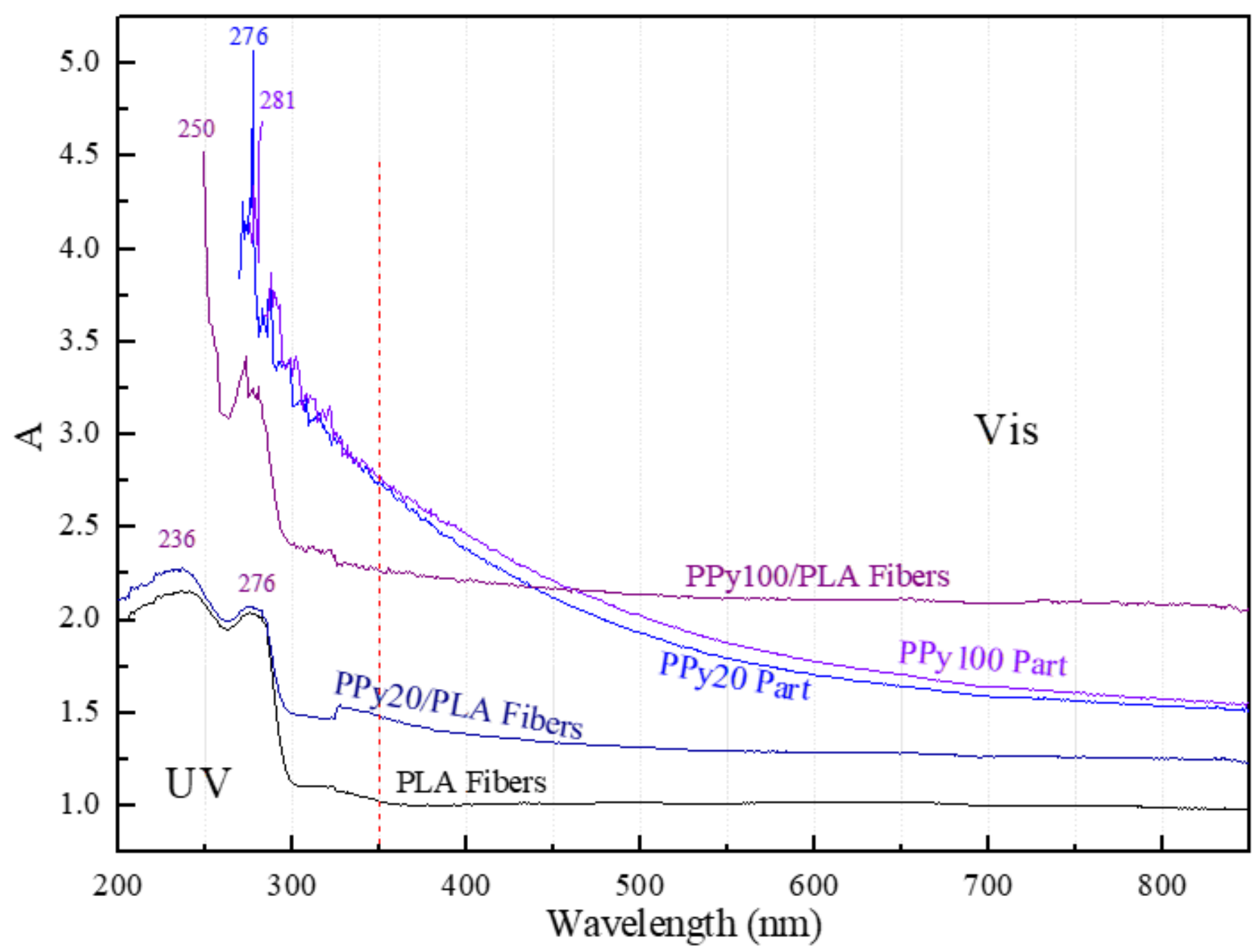

Figure 9

UV-Vis absorption of the particles and fibers of this work. Note the difference between the PPy100/PLA and PPy20/PLA fibers in the UV interval, which suggests a higher resonance in the first fibers. 